\title{
Forming and Coating of Hydroxyapatite on PEEK Substrate for Orthopedic Implants
}

\author{
Kittin Yutitum* \\ Biological Engineering Program, \\ King Mongkut's University of Technology, \\ Thonburi, Thailand
}

\author{
Anak Khantachawana \\ Biological Engineering Program, \\ Department of Mechanical Engineering, \\ King Mongkut's University of Technology, \\ Thonburi, Thailand
}

\begin{abstract}
Polyetheretherketone (PEEK) has been increasingly employed in mechanical properties in terms of strength, and PEEK can exhibit an elastic modulus closely to cortical bone (18 GPa). However, since PEEK is chemically inert with a hydrophobic surface, cell adhesion on the surface is one of the demerits. Therefore, the present research aims to improve cell adhesion on the PEEK surface by Hydroxyapatite (HA) coating. In this research, the pretreatment of the PEEK surface was performed by the sulfuric treatment. Then, coating of HA on the PEEK surface was performed via a wet chemical technique. In the wet chemical process, the concentration of calcium phosphate solution was varied from $1 \mathrm{X}$ to $2 \mathrm{X}$. The soaking temperature and duration were set at $37,60^{\circ} \mathrm{C}$ for 24 , and 72 hours. The results revealed that the wettability of the PEEK surface could be enhanced with sulfuric treatment. Contact angle decreased from 94 to 0 degrees before sulfuric treatment and HA coating, which showed super wetting. The XRD pattern and calcium phosphate ratio of the wet chemical coated specimen confirmed that HA structure was formed on the specimen surface which was operated under the proper wet chemical condition (1X_60C_24H). Furthermore, there was no significant change in the mechanical property of PEEK either before or after the whole process.
\end{abstract}

Keywords: Polyetheretherketone, Hydroxyapatite, Wet chemical technique, PEEK coating, Orthopedic

Received: 01 January 2020; Accepted: 13 February 2020; Published: 25 March 2020

\section{INTRODUCTION}

Common treatment of Degenerative Spine Disease (DSD) is to use a device called a "Cage" to replace damaged intervertebral discs (bone grafting) [1]. proposed to use the cage for spinal fusion. That time, Ti-6Al-4V was initially manufactured to produce a cage device for spinal fusion due to its excellent corrosion resistance and osseointegration [2, 3]. However, Ti-6Al-4V was degenerated into the vertebral bodies due to the difference in the modulus of elasticity that is the cause of "stress shielding effect" [4]. The DSD incidence rate typically increases with age in patients older than 60 years with a male and female ratio of 2:1. Although DSD is often found in the elderly, it can happen to the work aged as well [5]. There are some reports that patients with herniated disk were only 30 years of age, caused by bad behaviors that were not related to ergonomics. Furthermore, people with age over 30 years can also have herniated disc disease found in the spine area of the neck and lower waist with this disease. The patient usually has a pain in the area where the nerves are pressed and might also have numbness and muscle weakness [6]. Presently, the Cage is typically manufactured from Polyether ether ketone (PEEK) [7]. PEEK is a thermoplastic polymer with strength and mechanical properties appropriate to be a biomaterial [8], using in a load-bearing implant for spinal fusion and dental [9], which brings a high success rate in surgery and can support the force in a skeletal system [10]. The cage can

\footnotetext{
${ }^{*}$ Correspondence concerning this article should be addressed to Kittin Yutitum, Biological Engineering Program, King Mongkut's University of Technology, Thonburi, Thailand. E-mail: kittin.yut@gmail.com

(c) 2020 The Author(s). Published by KKG Publications. This is an Open Access article distributed under a Creative Commons AttributionNonCommercial-NoDerivatives 4.0 International License.
} 
contain pieces of HA to help stimulate bone graft (regeneration) and enhance the integration between the hiatus in the intervertebral space, resulting in less recovery time after surgery. The biocompatibility of the PEEK is powerfully affected by its surface characteristics, including the surface roughness, chemical composition and wettability [11]. The Young's modulus of PEEK is approximately 3 to $4 \mathrm{GPa}$, which is relatively similar to the cortical bone ( 7 to $30 \mathrm{GPa}$ ). PEEK is a very inert polymer in the biological system and hydrophobic [12, 11, 13]. Such that, it does not allow protein adsorption, cell adhesion, and bone integration (osseointegration) to the surface of PEEK, causing a long time to recuperate after the surgery [14]. A common method to improve osseointegration is to coat PEEK substrate with HA. One of the most effectual techniques for creating an HA coating layer is the wet chemical techniques [14], which mimics the mineralization process of bone, namely "Biomimetics" [15]. The decrease in local $\mathrm{pH}$ leads to partial dissolution of the coating and subsequent calcium and phosphate release into $\mathrm{Ca}^{+}$and $\mathrm{PO}_{4}^{-}$respective ionic forms because acidic $\mathrm{pH}$ predominates at inflammatory locate. The implant locate increases the saturation of body fluids and precipitates a biological apatite onto the surface of the implant [16]. This layer of biological apatite might contain proteins and operated as a matrix for osteogenic cell attachment and growth [17]. This biological apatite layer helps to enhance the bone healing process around the implant. Furthermore, acid-treatments have beneficial in improving the adhesion of HA on PEEK [18]. Therefore, the present study focuses on coating HA on PEEK surface by applying acid-treatments and a wet chemical process. The effect of calcium-phosphate-solution concentration, soaking temperature and soaking duration using the wet chemical process on formation of HA structure was discussed.

\section{EXPERIMENTAL}

\section{A. Materials and Methods}

Biomedical-grade Polyether Ether Ketone (PEEK) was mechanically polished with 2000 grit sandpaper using a polishing machine. The specimens with a rectangular shape (square $1 \times 1 \mathrm{~mm}$, thickness $1 \mathrm{~mm}$ ) were cleaned by an ultrasonic cleaning machine for 15 minutes in acetone, $70 \%$ ethanol, and double-distilled water. In order to increase the surface area for HA adhesion, PEEK specimens were chemical-etched with sulfuric acid at a concentration of $90 \%$ for 1 minute. The experiment was performed inside a beaker on the ice to prevent the danger of a severe exothermic chemical reaction.

\section{B. Preparation of the Supersaturated Calcium Phos-} phate (CaP) Solution

The analytical reagent grade of $\mathrm{CaCl}_{2} \bullet 2 \mathrm{H}_{2} \mathrm{O}$ was dissolved in double-distilled water and buffered at $\mathrm{pH} 7.2$ with Hepes (Calcium solution). The analytical reagent grade of $\mathrm{Na}_{3} \mathrm{PO}_{4} \bullet 12 \mathrm{H}_{2} \mathrm{O}$ and $\mathrm{NaHCO}_{3}$ was also dissolved in double distilled water and buffered at $\mathrm{pH} 7.2$ with Hepes (Phosphate solution). The $\mathrm{pH}$ of the solution must be adjusted at 7.2 for chemical action to synthesized HA. The PEEK polymer has a surface negative charge (the zeta potential of PEEK polymers is negative at $\mathrm{pH}$ more than 6) [19, 20]. It was analyzed HA powder and analyze adhesive strength of the HA layer. Calcium phosphate supersaturated calcifying solution was freshly prepared by mixing $500 \mathrm{ml}$ of the calcium solution and $500 \mathrm{ml}$ of the phosphate solution. The specimen was immersed in solution with different conditions such as calcium phosphate solution concentration, temperature, and time shown in Table 1.

TABLE 1

WET CHEMICAL COATING CONDITIONS

\begin{tabular}{llllll} 
Temperature $\left(^{\circ}\right)$ & \multicolumn{3}{c}{37} & \multicolumn{2}{c}{60} \\
\hline & & & & \\
CaP Concentration Time (h) & $1 \mathrm{X}$ & $2 \mathrm{X}$ & $1 \mathrm{X}$ & $2 \mathrm{X}$ \\
& 24 & 72 & 24 & 72 \\
\hline
\end{tabular}

\section{Physicochemical Characterization of $H A$}

1) Inductively Coupled Plasma Optical Emission Spectrometer (ICP-OES): The calcium and phosphorus content of HA synthesized on PEEK substrate after coating in the $\mathrm{CaP}$ solution can be determined. After digesting $5 \mathrm{mg}$ of $\mathrm{HA}$ in $1 \mathrm{ml}$ of $\mathrm{HCl}$, it was diluted $10 \mathrm{X}$ with double-distilled water.

2) X-Ray Diffractometer (XRD): Crystal structure from each compounds in HA can be detected by X-ray diffractometer with 20 varying from 20 to 60 degree using $\mathrm{Cu}$ $\mathrm{K} \alpha$ radiation at $0.2^{\circ}$ step size. The established presence of HA crystalline phases found as the HA peaks, correspondingly.

3) Fourier Transform Infrared spectroscopy (FTIR): The spectrophotometer with wavelength $500-4000 \mathrm{~cm}^{-1}$ was used to determine the functional groups in HA molecules by scanning the wet chemical HA sample. One of the objectives of the FTIR analysis was to ensure that certain important groups (namely $\mathrm{PO}_{4}$ ), that are essential for the performance of HA. 


\section{Characterization of the HA-coated PEEK}

1) Scanning Electron Microscopes (SEM): The specimen surface was coated with gold by using the sputtering method to improve the observed surface's electrical conductivity. Then, the morphology of the HA coating surface was observed by SEM. Sputter coating is to acquire good results by providing a protective layer to the samples under high voltage of SEM. Then, the morphology of the HA coating surface was observed by SEM

2) Contact angle: Contact angle between the PEEK surface and water was measured by digital camera following by image analysis method. The contact angle measurement is used to determine the wettability of PEEK surface [21]. The 3 ul of water is dropped on the PEEK surface and snap a picture of droplet by digital camera. Contact angle between the PEEK surface and water droplet is analyzed by ImageJ software. The contact angle is required to perform a contact angle between the PEEK substances and liquid (water). It quantifies hydrophobic or hydrophilic of the HA coating layer. The contact angle measurement can be divided into three steps: light source, camera and horizontal stage.

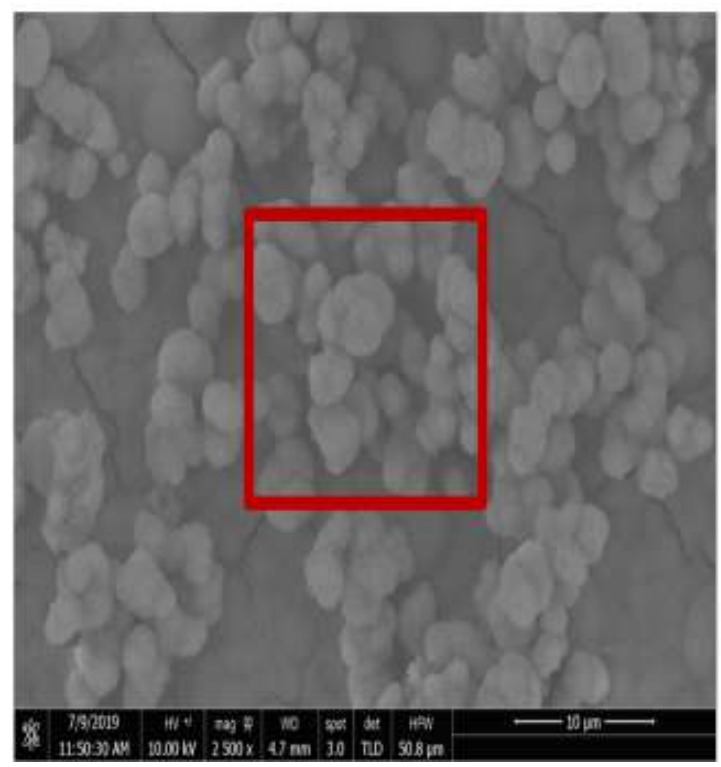

Fig. 1. SEM micrograph of (left) plane view and (right) EDS spectra of the wet chemical HA coating on PEEK substrate

Inductively coupled plasma optical emission spectrometry (ICP-OES) experiment was conducted to confirm $\mathrm{Ca} / \mathrm{P}$ molar ratio of $\mathrm{HA}$. The calcium and phosphorus content of HA synthesized on the PEEK substrate after coating in the $\mathrm{CaP}$ solution can be determined. $\mathrm{Ca} / \mathrm{P}$ mole ratios of the HA produced via wet chemical technique

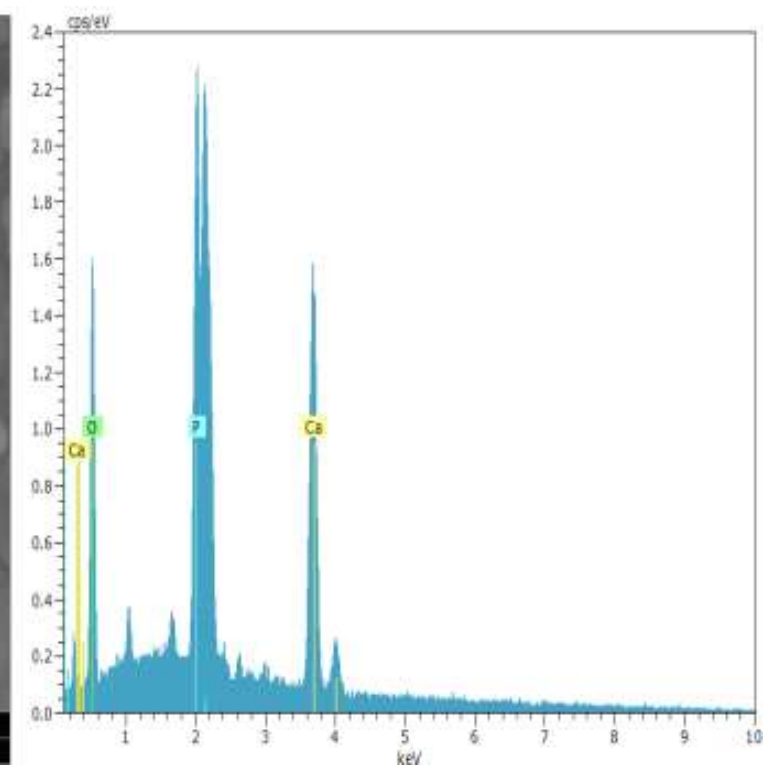

3) Micro vickers hardness The specimen was tested by micro-Vickers hardness indenter with indentation force of $0.01 \mathrm{~N}$ and holding times of $10 \mathrm{~s}$. The hardness is calculated as the load quotient on the square area of the indentation. Normal loads increased linearly until reaching the maximum value after $10 \mathrm{~s}$. The hardness is calculated as the load quotient on the square area of the indentation.

\section{RESULTS AND DISCUSSION}

\section{A. Synthesis of HA by Wet Chemical Technique}

By the wet chemical process, the CaP solution was unstable (supersaturated solution). After the PEEK polymer was immersed in a clear $\mathrm{CaP}$ solution, it will become clouded and precipitate on the bottom. The white precipitate is synthesized hydroxyapatite in this process. Fig.1 shows selecting elemental quantity analysis at a red square. EDS analysis can confirm HA as a product of the wet chemical process. EDS spectra revealed oxygen, calcium, and phosphorus peaks, showing good agreement with chemical composition in $\mathrm{Ca}_{5}\left(\mathrm{PO}_{4}\right)_{3} \mathrm{OH}$. Therefore, HA crystallite would form corresponding to the theory of nucleation. HA can be confirmed as a product from wet chemical techniques by EDS analysis.

were confirmed by the ICP-OES experiment. The result shows that the average $\mathrm{Ca} / \mathrm{P}$ ratio decreases with decreasing calcium-phosphate-solution concentration. Further, the $\mathrm{Ca} / \mathrm{P}$ ratio of the specimen, synthesized under the $1 \mathrm{X}$ solution at $60^{\circ} \mathrm{C}$ for 24 hours, is closed to the stoichiometry of HA (1.67), shown in Table 2. 
TABLE 2

ELEMENTAL CONCENTRATIONS OF THE WET CHEMICAL HA DETERMINED BY ICP-OES

\begin{tabular}{cccc}
\multicolumn{3}{c}{ Wet Chemical Synthesis Conditions } & $\mathrm{Ca} / \mathrm{P}$ \\
\hline $37^{\circ}$ & $1 \mathrm{X}$ & $24 \mathrm{~h}$ & 1.59 \\
& & $72 \mathrm{~h}$ & 1.55 \\
& $2 \mathrm{X}$ & $24 \mathrm{~h}$ & 1.64 \\
& & $72 \mathrm{~h}$ & 1.61 \\
$60^{\circ}$ & $1 \mathrm{X}$ & $24 \mathrm{~h}$ & 1.67 \\
& & $72 \mathrm{~h}$ & 1.59 \\
& $2 \mathrm{X}$ & $24 \mathrm{~h}$ & 1.65 \\
& & $72 \mathrm{~h}$ & 1.60 \\
\hline
\end{tabular}

HA was obtained by wet chemical technique. Crystal structure of specimens were investigated by XRD machine. A peak in intensity occurs when the HA contains lattice planes with d-spacings appropriate to diffract $\mathrm{X}$-rays at that value of $\theta$. Including crystal structure from each compounds in HA, it can be detected by X-ray diffractometer with positions $(2 \theta)$ varying from 20 to 60 degree.

Fig. 2 shows XRD patterns of the wet chemical HA compared with HA standard (ICDD 9-432) [22], which is confirmed that the peaks $(211,112,300)$ of HA fabricated by the wet chemical process corresponded with the HA standard [23, 22]. In other words, HA crystalline can be formed on the PEEK surface by the wet chemical process. However, the concentration of calcium phosphate solution influenced the crystallization of hydroxyapatite measured by the sharpness and narrowness of each peak in XRD results.

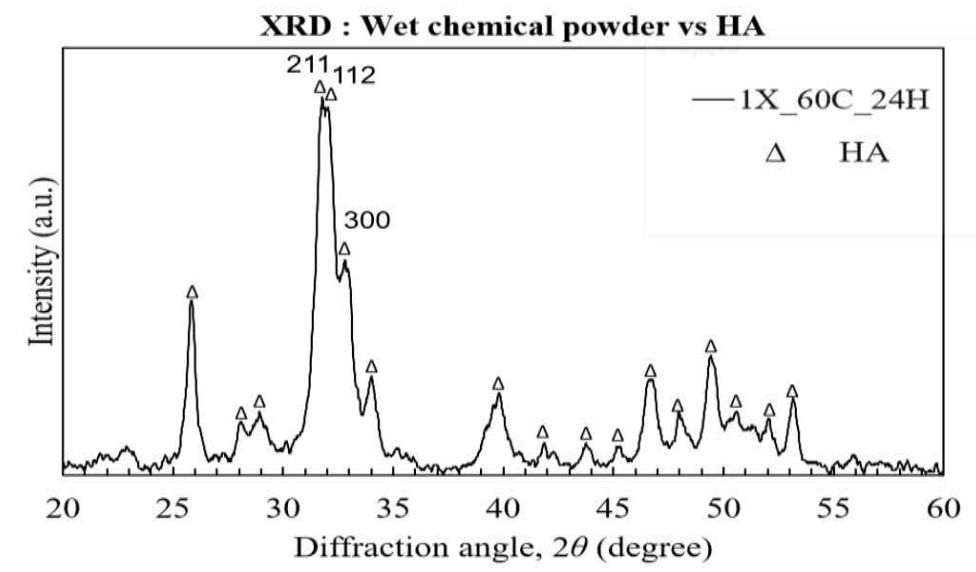

Fig. 2. XRD patterns of the wet chemical HA comparing with HA standard (ICDD 9-432)

The spectrophotometer with wavelength 500 - 4000 $\mathrm{cm}^{-1}$ was used to determine the functional groups in HA molecules by scanning the wet chemical HA sample. Fig. 4 shows comparison of functional group between the synthesized HA and HA commercial product (HAP 200, Taihei Chemical Industrial Co., Ltd.). IR absorption bands at the wavelength of 560,600, 870, 960, 1020, and $1100 \mathrm{~cm}^{-1}$ represent the phosphate group, IR absorption bands at the wavelength of $640 \mathrm{~cm}^{-1}$ represent hydroxide group. Fig. 3 shows the FTIR pattern of the wet chemical HA (1X_60C_24H condition) compared with the commercialized HA (HAP 200). $\mathrm{PO}_{4}^{3-}$ in the FTIR spectrum of HA synthesized were found. It can easily be observed that the spectra follow the HA characteristic spectrum. $\mathrm{PO}_{4}^{3-}$ group forms intensive IR absorption bands at 560, 600 and $1100 \mathrm{~cm}^{-1}$. The chemical groups of HA were matched with HA commercial grade (HAP 200, Taihei Chemical Industrial Co., Ltd.). 
Fourier Transform Infrared Spectrophotometer (FTIR)

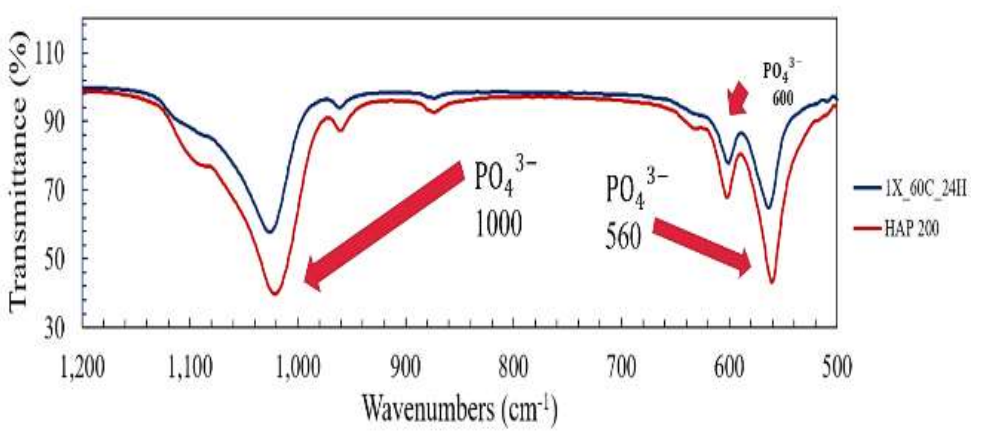

Fig. 3. FTIR pattern of wet chemical HA comparing with commercialize HA (HAP200)

\section{B. Surface Micrograph and of $H A$}

Fig. 4 shows the contact angle of the specimens (including bare-PEEK, Polished-PEEK, sulfuric acid treatedPEEK, and wet chemical HA coating-PEEK), which were equaled to $93^{\circ}, 76^{\circ}, 68^{\circ}$, and $0^{\circ}$, respectively. In order to preserve the mechanical property, the untreated PEEK was etched with the sulfuric concentration at $90 \%$ for 1 min. The result of chemical etching represents a smaller contact angle that increases the HA coating layer [24]. Moreover, sulfuric acid is required to modify the PEEK surface to be smaller than Bare-PEEK. The etching technique significantly affects wetting behavior.

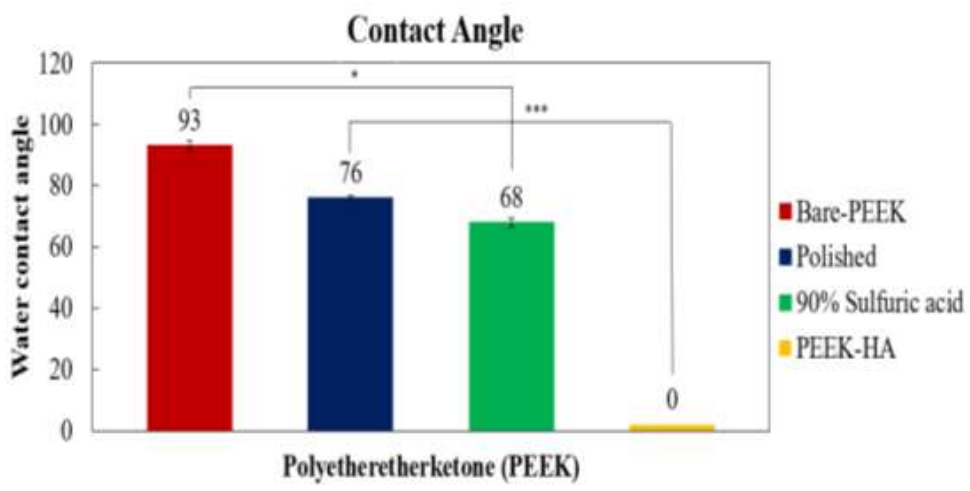

Fig. 4. Contact angle of PEEK

The micro Vickers Hardness (HV) measurement was carried out on a micro-hardness tester with indentation force of $0.01 \mathrm{~N}$ for $10 \mathrm{sec}$ on PEEK. Vickers hardness for HA-coated PEEK is in the range of 24.5-27.5 HV. Fig. 4 shows micro Vickers hardness of bare-PEEK and PEEK treated with sulfuric acid. The measured hardness value of PEEK treated with sulfuric acid (HV $=26.97 \pm$ 0.68 ) was increased by approximately $10 \%$ higher than bare-PEEK specimens $(\mathrm{HV}=24.65 \pm 0.88)$. The values of the obtained results differ due to the treatment conditions and the deposition method for PEEK coatings, which influences the uniformity of coatings.

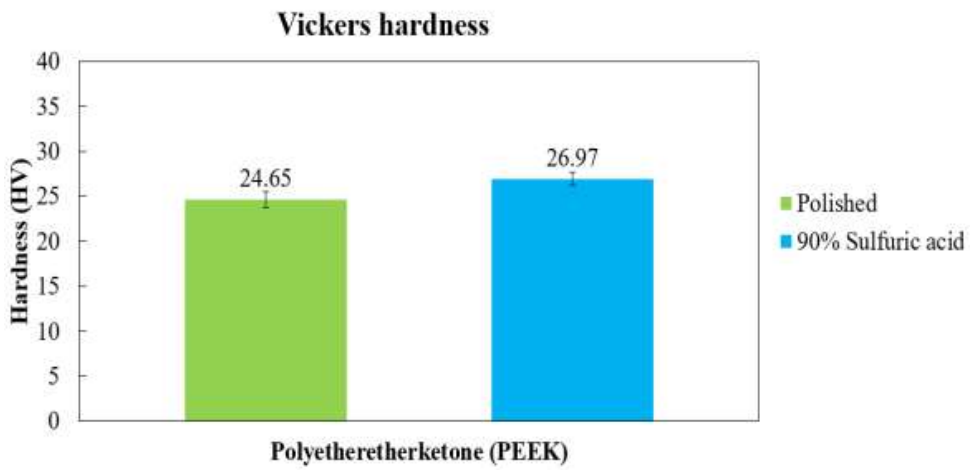

Fig. 5. Vickers microhardness values of bare-PEEK and PEEK treated with sulfuric acid 


\section{CONCLUSION}

This study provides evidence for the mechanical of PEEK coated HA. The adhering ability of HA on the PEEK surface was improved by reducing the water contact angle of the surface, which was induced by polishing and sulfuric treatment. When sulfuric treatment was applied to the PEEK surface, sulfuric-treated PEEK has a hardness higher than bare PEEK, but there was no significant difference. Further, the sulfuric treatment shows no toxicity effect on the PEEK surface. The wet chemical condition was able to synthesize HA on the PEEK surface. The synthesized HA layer has a crystal structure. The wet chemical technique is able to synthesize the HA corresponding to the commercial HA product. In addition, the findings confirm the hydroxyapatite effects from the wet chemical technique in the PEEK-HA specimen may prove superior healing efficacy compare to bare-PEEK and sulfuric treated PEEK. Furthermore, uniform dispersion of HA layer on PEEK surface was ably achieved in a day. The paper suggests that the wet chemical technique can be successfully applied to coat the PEEK substrate.

\section{REFERENCES}

[1] T. Scarabino and S. Pollice, Imaging spine after treatment. Milan, Italy: Springer-Verlag, 2014.

[2] S. Seaman, P. Kerezoudis, M. Bydon, J. C. Torner, and P. W. Hitchon, "Titanium vs. polyetheretherketone (peek) interbody fusion: Meta-analysis and review of the literature," Journal of Clinical Neuroscience, vol. 44, pp. 23-29, 2017. doi: https: //doi.org/10.1016/j.jocn.2017.06.062

[3] N. Bernhard, S. Berner, M. De Wild, and M. Wieland, "The binary TiZr alloy-a newly developed ti alloy for use in dental implants," Forum Implantol, vol. 5, pp. 30-39, 2009.

[4] J. Wolff, "Das gesetz der transformation der knochen," DMW-Deutsche Medizinische Wochenschrift, vol. 19, no. 47, pp. 1222-1224, 1893. doi: https://doi.org/10.1055/s-0028-1144106

[5] TCDC Resource Center. Aging society vs. aged society in global and Thai context. [Online]. Available: https://bit.ly/3L2Hbry

[6] J. Jordan, K. Konstantinou, and J. O'Dowd. (2009) Herniated lumbar disc. [Online]. Available: https://bit.ly/32O0a8f

[7] ASTM International. (2017) Standard specification for Polyetheretherketone (PEEK) polymers for surgical implant applications. [Online]. Available: https://www.astm.org/f2026-17.html

[8] G. W. Bagby, "Arthrodesis by the distractioncompression method using a stainless steel implant,"
Orthopedics, vol. 11, no. 6, pp. 931-934, 1988. doi: https://doi.org/10.3928/0147-7447-19880601-13

[9] S. Ramakrishna, J. Mayer, E. Wintermantel, and K. W. Leong, "Biomedical applications of polymercomposite materials: A review," Composites Science and Technology, vol. 61, no. 9, pp. 1189-1224, 2001. doi: https://doi.org/10.1016/S0266-3538(00) 00241-4

[10] R. J. Kroeze, M. N. Helder, L. E. Govaert, and T. H. Smit, "Biodegradable polymers in bone tissue engineering," Materials, vol. 2, no. 3, pp. 833-856, 2009. doi: https://doi.org/10.3390/ma2030833

[11] C.-M. Han, E.-J. Lee, H.-E. Kim, Y.-H. Koh, K. N. Kim, Y. Ha, and S.-U. Kuh, "The electron beam deposition of titanium on Polyetheretherketone (PEEK) and the resulting enhanced biological properties," Biomaterials, vol. 31, no. 13, pp. 3465-3470, 2010. doi: https://doi.org/10.1016/j. biomaterials.2009.12.030

[12] T. Kizuki, T. Matsushita, and T. Kokubo, "Apatiteforming peek with $\mathrm{TiO}_{2}$ surface layer coating," Journal of Materials Science: Materials in Medicine, vol. 26, no. 1, p. 41, 2015.

[13] G. Altankov and T. Groth, "Reorganization of substratum-bound fibronectin on hydrophilic and hydrophobic materials is related to biocompatibility," Journal of Materials Science: Materials in Medicine, vol. 5, no. 9, pp. 732-737, 1994. doi: https://doi.org/10.1007/BF00120366

[14] T. J. Dennes and J. Schwartz, "A nanoscale adhesion layer to promote cell attachment on PEEK," Journal of the American Chemical Society, vol. 131, no. 10, pp. 3456-3457, 2009. doi: https://doi.org/10.1021/ ja810075c

[15] A. Bigi, E. Boanini, B. Bracci, A. Facchini, S. Panzavolta, F. Segatti, and L. Sturba, "Nanocrystalline hydroxyapatite coatings on titanium: A new fast biomimetic method," Biomaterials, vol. 26, no. 19, pp. 4085-4089, 2005. doi: https://doi.org/10.1016/j. biomaterials.2004.10.034

[16] W. Kirkaldy-Willis, "Presidential symposium on instability of the lumbar spine: Introduction," Spine, vol. 10, no. 3, p. 254, 1985.

[17] D. K. Sengupta, "Clinical biomechanics of the spine," Spine, vol. 42, 2017. doi: https://doi.org/ 10.1097/BRS.0000000000002019

[18] O. Sproesser, P. R. Schmidlin, J. Uhrenbacher, M. Roos, W. Gernet, B. Stawarczyk et al., "Effect of sulfuric acid etching of polyetheretherketone on the shear bond strength to resin cements," The Journal 
of Adhesive Dentistry, vol. 16, no. 5, pp. 465-472, 2014.

[19] J. Ma, C. Wang, and C. Liang, "Colloidal and electrophoretic behavior of polymer particulates in suspension," Materials Science and Engineering: $C$, vol. 27 , no. 4 , pp. $886-889,2007$. doi: https://doi.org/10.1016/j.msec.2006.10.005

[20] H. Yue, L. Yuan, W. Zhang, S. Zhang, W. Wei, and G. Ma, "Macrophage responses to the physical burden of cell-sized particles," Journal of Materials Chemistry B, vol. 6, no. 3, pp. 393-400, 2018. doi: https://doi.org/10.1039/C7TB01673E

[21] Ossila. (2021) Contact angle: A guide to theory and measurement. [Online]. Available: https://bit.ly/3rqqNK1
[22] ASTM International. (2016) Standard specification for composition of hydroxylapatite for surgical implants. [Online]. Available: https://bit.ly/3J9XxNF

[23] S. Shahabi, F. Najafi, A. Majdabadi, T. Hooshmand, M. Haghbin Nazarpak, B. Karimi, and S. M. Fatemi, "Effect of gamma irradiation on structural and biological properties of a PLGA-PEG-hydroxyapatite composite," The Scientific World Journal, vol. 2014, pp. 1-9, 2014. doi: https://doi.org/10.1155/2014/ 420616

[24] J. M. Toth and H. S. An, "Biomaterials, bone grafts and substitutes, biomaterials, and osteoinductive substances in spinal instrumentation," in Spinal Instrumentation, A. H. S. and J. Cotler, Eds. Baltimore, MD: Lippincott, Williams \& Wilkins, 1999. 